\title{
BMJ Open Validation of newly developed and redesigned key indicator methods for assessment of different working conditions with physical workloads based on mixed-methods design: a study protocol
}

\author{
Andre Klussmann, ${ }^{1,2}$ Falk Liebers, ${ }^{3}$ Felix Brandstädt, ${ }^{3}$ Marianne Schust, ${ }^{3}$ \\ Patrick Serafin, ${ }^{1}$ Andreas Schäfer, ${ }^{1}$ Hansjürgen Gebhardt, ${ }^{1}$ Bernd Hartmann, ${ }^{4}$ \\ Ulf Steinberg ${ }^{3}$
}

To cite: Klussmann A, Liebers F, Brandstädt F, et al. Validation of newly developed and redesigned key indicator methods for assessment of different working conditions with physical workloads based on mixed-methods design: a study protocol. BMJ Open 2017;7:e015412. doi:10.1136/ bmjopen-2016-015412

- Prepublication history for this paper is available online. To view these files please visit the journal online (http://dx.doi org/10.1136/bmjopen-2016015412).

AK and FL contributed equally.

Received 2 December 2016 Revised 18 April 2017

Accepted 17 May 2017

CrossMark

For numbered affiliations see end of article.

Correspondence to Dr Andre Klussmann; klussmann@institut-aser.de, klussmann@uni-wuppertal.de

\begin{abstract}
Introduction The impact of work-related musculoskeletal disorders is considerable. The assessment of work tasks with physical workloads is crucial to estimate the work-related health risks of exposed employees. Three key indicator methods are available for risk assessment regarding manual lifting, holding and carrying of loads; manual pulling and pushing of loads; and manual handling operations. Three further KIMs for risk assessment regarding whole-body forces, awkward body postures and body movement have been developed de novo. In addition, the development of a newly drafted combined method for mixed exposures is planned. All methods will be validated regarding face validity, reliability, convergent validity, criterion validity and further aspects of utility under practical conditions.
\end{abstract}

Methods and analysis As part of the joint project MEGAPHYS (multilevel risk assessment of physical workloads), a mixed-methods study is being designed for the validation of KIMs and conducted in companies of different sizes and branches in Germany. Workplaces are documented and analysed by observations, applying KIMs, interviews and assessment of environmental conditions. Furthermore, a survey among the employees at the respective workplaces takes place with standardised questionnaires, interviews and physical examinations. It is intended to include 1200 employees at 120 different workplaces. For analysis of the quality criteria, recommendations of the COSMIN checklist (COnsensusbased Standards for the selection of health Measurement INstruments) will be taken into account.

Ethics and dissemination The study was planned and conducted in accordance with the German Medical Professional Code and the Declaration of Helsinki as well as the German Federal Data Protection Act. The design of the study was approved by ethics committees. We intend to publish the validated KIMs in 2018. Results will be published in peer-reviewed journals, presented at international meetings and disseminated to actual users for practical application.

\section{Strengths and limitations of this study}

- This research project will provide a scientific substantiation and-if necessary according to the results of the study-modification of standardised methods to assess physical workloads at a screening level.

- With the help of these KIMs, the full range of physical workloads (excluding exposures due to hand-transmitted and whole-body vibration) could be assessed by occupational health and safety stakeholders.

- Knowledge about the correlation between workrelated factors and musculoskeletal disorders will be advanced.

- The study is limited by the cross-sectional design, which is not suitable to assess the causal relationship between variables but only associations.

\section{INTRODUCTION}

General background

Work-related musculoskeletal disorders (WRMSDs) have been recognised for many decades. ${ }^{12}$ Disorders often mentioned in the literature include low back pain and intervertebral disc diseases, ${ }^{3}$ epicondylitis ${ }^{4}$ and carpal tunnel syndrome. ${ }^{5}$ Hard physical work may also lead to high cardiovascular strain and may increase the mortality risk of ischaemic heart disease in individuals with a low or moderate fitness level. ${ }^{6}$

According to the European Council Directive 89/391/ EEC of 12 June 1989 on the introduction of measures to encourage improvements in the safety and health of workers at work, the employer must perform an assessment of the risks to safety and 


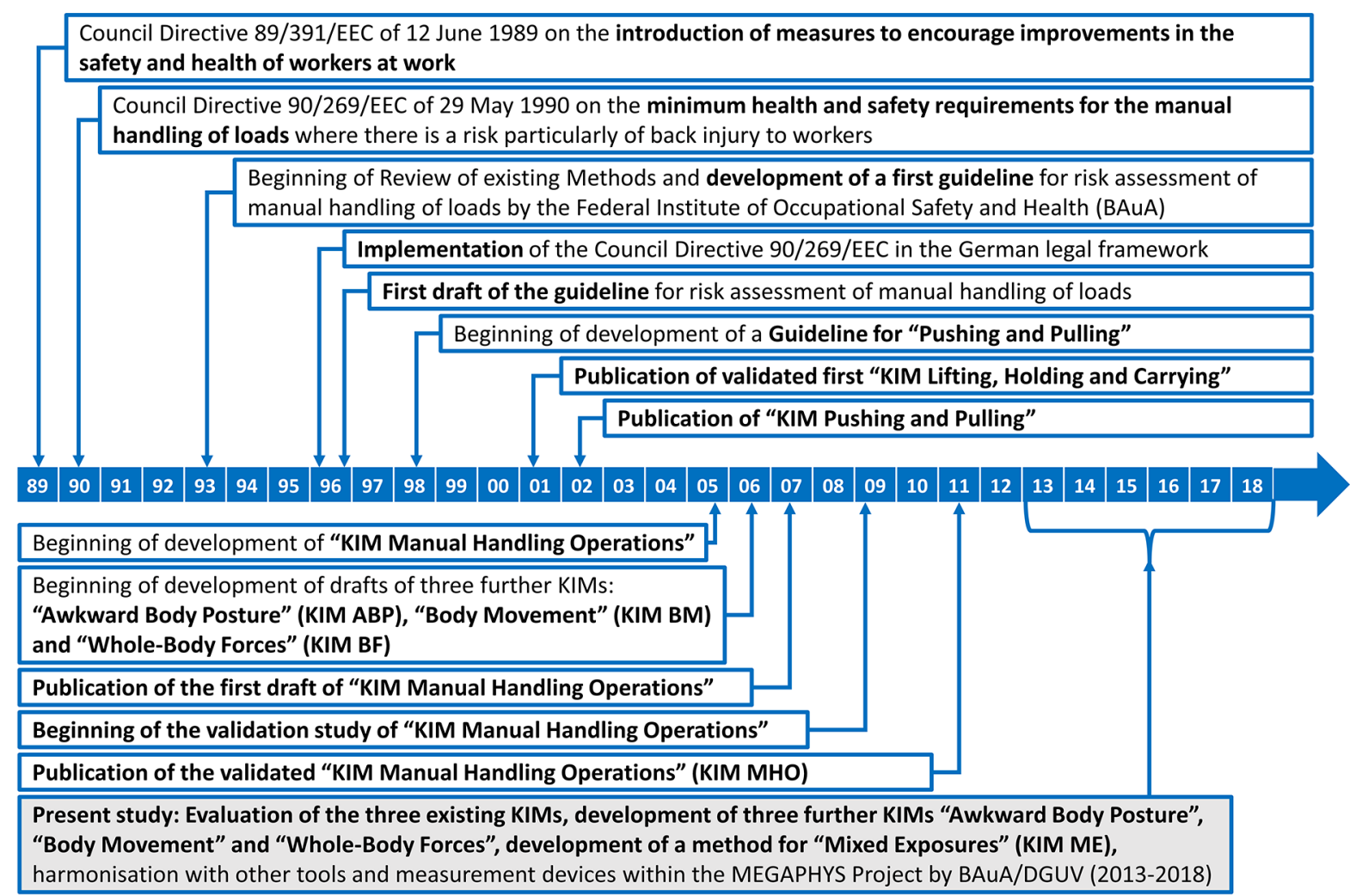

Figure 1 Development of the key indicator methods (KIMs) for the risk assessment of physical workloads since the year 1989. The horizontal arrow indicates the years of the development process.

health at work, including those to which specific groups of workers are exposed. ${ }^{7}$ One year later, a further European Council Directive 90/269/ EEC 'manual handling of loads' of 29 May 1990 was published addressing the minimum health and safety requirements for the manual handling of loads where there is a risk particularly of back injury to workers. ${ }^{8}$ To assess the risk of WRMSDs, a number of assessment methods have been developed. ${ }^{9}$

The risk assessment of physical workloads is a basic necessity to derive purposeful prevention measures. Beside the legal requirements mentioned above, ergonomic interventions usually have financial merits. Within a systematic review, from a company perspective, strong evidence was found in support of the financial merits of ergonomic interventions in the manufacturing and warehousing sector; moderate evidence, in the administrative support and healthcare sectors; and limited evidence, in the transportation sector. ${ }^{10}$

\section{Previous development and validation of the KIMs}

In Germany, the release of the two European Council directives triggered the development of 'key indicator methods' (KIMs) (see figure 1). The KIMs were developed for risk assessment at the screening level in the case of physical workloads. Potential users include occupational safety and health stakeholders and industrial engineers in companies as well as ergonomists, occupational health physicians, employers and employees associations, and insurance companies or research facilities.
Three different KIM worksheets, one for lifting, holding, carrying loads (KIM-LHC); one for pulling and pushing loads (KIM-PP); and one for manual handling operations (KIM-MHO), are available so far. These methods were developed by the Federal Institute for Occupational Safety and Health (BAuA) in close collaboration with practitioners, safety representatives, occupational health physicians and the 'Länderausschuss für Arbeitsschutz und Sicherheitstechnik' (Federal Committee of the States for Occupational Safety and Health). ${ }^{11-13}$ Briefly, work characteristics such as force, frequency and duration and general working conditions are assessed by means of the KIM, and a score is calculated to summarise the work-associated risk for adverse health outcomes, for example, musculoskeletal symptoms. To illustrate the result, the score is transformed into a traffic light scale indicating a low exposure situation where physical overload is unlikely to occur (green), situations with slightly increased (greenish yellow) and substantially increased (yellow) exposure, up to a high exposure situation where physical overload is likely to occur and a redesign of the workplace is probably necessary (red). ${ }^{14}$ The current existing methods can be downloaded from the homepage of BAuA. ${ }^{15}$ The three existing KIMs deal with manual handling of loads and repetitive manual handling operations. Further aspects of physical workloads, such as awkward body posture, whole-body forces and body movement, have not or not sufficiently been included in this 
method inventory yet. In order to fill this gap, drafts of three supplemental methods were developed. Further developments are necessary, and a revision of the three existing methods is required, so that all six methods are compatible. In addition, the development of a method for the assessment of mixed physical workloads is planned.

\section{Preliminary work: development of new KIM drafts}

The preliminary work during the last decades mentioned above (see figure 1) was complemented by an additional search of peer-reviewed articles and grey literature predominantly in German and English. Various other methods for the assessment of working conditions associated with physical workloads were analysed systematically. The various methods included on the one hand a large number of work characteristics considered to be related to health outcomes and on the other hand a large number of different body regions, symptoms and diseases which could be affected by these work characteristics. There is only low evidence of a 'cause and effect model' or even a 'dose-response relationship' with certainty between most physical workloads and musculoskeletal disorders (MSDs). In the published studies or methods, the selection of the observed characteristics varied significantly. Unfortunately, details about the selection of the parameters were often not indicated in the publications available, and many questions remain, for example, questions about the deduction or the combination of the parameters to be assessed for description of work-related risks. In addition, only a small number of methods assessing biomechanical exposures in occupational settings have been tested in a systematic manner for validity, reliability or other aspects related to their practical use. ${ }^{9}$

The development of the new KIM drafts was based on a comprehensive and critical literature review of the methods mentioned above. This knowledge was combined with interviews about typical kinds of exposures and exposure structures of physical workloads, involving scientists, supervisors of state agencies and professional associations, occupational physicians, occupational health and safety officers, and managers from companies in various industries. Finally, the drafts of three new KIMs (wholebody forces, awkward postures and body movement) were available for validation within the present study.

\section{METHODS AND ANALYSIS}

\section{Aim, design and setting}

In this study protocol, the concept for development and validation of the newly developed and redesigned KIMs is presented. It is part of a joint project (MEGAPHYS, Mehrstufige Gefährdungsanalyse physischer Belastungen am Arbeitsplatz (multilevel risk assessment of physical workloads)). The distribution of the responsibility for the recruitment and documentation of the workplaces and the realisation of the interviews of further partners in the joint project are described in the 'Funding' and
'Acknowledgements' sections. General aims, definition of the six types of physical workloads used and the background of the joint project MEGAPHYS have been described previously. ${ }^{16}$

The aim of the study protocol presented here is to provide the concept of how to validate the revised versions of the three existing KIMs (KIM-LHC, KIM-PP and KIM-MHO) and the draft versions of the three new KIMs for whole-body forces, awkward postures, and body movement (KIM-ABP, KIM-BF and KIM-BM) in order to provide validated risk assessment methods for these six types of physical workloads. Furthermore, a draft of an additional KIM for the assessment of mixed physical workloads, including relevant indicators of the six specific KIMs, is also planned (see tables 1 and 2). The 'combined KIM' will be developed during the study based on the key indicators of the six KIMs. Different mathematical models will be tested and enhanced iteratively. Since this method is not fixed at the beginning of the validation study, we will only be able to disseminate a draft of a combined method and not a fully validated method at the end of this project.

A number of methods for the risk assessment of physical workload already exist. ${ }^{9}$ These methods are of very different extents and qualities, from simple checklists to comprehensive methods with extensive testing of different quality criteria (eg, tested in several cross-sectional studies and longitudinal studies). A disadvantage of these methods is that they are often only 'single solutions'. That means, they focus on one type of physical workload (eg, load handling), and the different methods have different risk scales. If someone wants to assess several different types of physical workload at a workplace, he or she must use different methods and obtain different results (eg, a risk index at NIOSH Lifting Equation ${ }^{17}$ or risk categories at Rapid Entire Body Assessment $\left.(\mathrm{REBA})^{18}\right)$. The reason for this project is to have one system with a uniform risk concept and cover all the main types of physical workloads. The division into the six different types of physical workloads presented here has mainly pragmatic reasons: these are distinguishable types of physical workloads which can be identified and assessed by the practical user.

The main objective to be considered is the association between physical workloads, as assessed by means of the scores of the KIMs, and the frequency of musculoskeletal symptoms and other outcomes within the exposed workers in terms of discriminative capacity of the six KIMs or the newly drafted combined KIM.

The validation of KIM uses a cross-sectional design and a mixed-methods approach. For the determination of criterion validity, a cross-sectional study among 1200 employees at approximately 120 different workplaces will be carried out. Workplace analyses will be done by direct observations and assessments using the KIMs, interviews of employees and managers, workplace measurements (eg, noise, climate) and video recordings. Exposures are analysed and documented by members of the study team. The workplace analyses will also be used for the 


\begin{tabular}{|c|c|c|c|}
\hline Acronym & $\begin{array}{l}\text { Focus of this key indicator } \\
\text { method (KIM) }\end{array}$ & $\begin{array}{l}\text { Key indicators to be considered in this } \\
\text { KIM in the revised version }\end{array}$ & Examples \\
\hline KIM-PP & $\begin{array}{l}\text { Manual pushing and pulling of } \\
\text { loads with trucks and monorails }\end{array}$ & $\begin{array}{l}\text { Daily duration and distance* } \\
\text { Load weight/transport device* } \\
\text { Driveway conditions } † \\
\text { Properties of transport device } † \\
\text { Body posture } \\
\text { Unfavourable working conditions }{ }^{\star} \\
\text { Work organisation/distribution of this type of } \\
\text { physical workload during the shift } \dagger\end{array}$ & $\begin{array}{l}\text { Postal service with cart, } \\
\text { picking with containers, } \\
\text { waste disposal }\end{array}$ \\
\hline KIM-MHO & $\begin{array}{l}\text { Manual handling operations: } \\
\text { work tasks with uniform, } \\
\text { repetitive motion and } \\
\text { predominantly lower force } \\
\text { expenses of the upper } \\
\text { extremities during } \mathrm{MHO}\end{array}$ & $\begin{array}{l}\text { Daily duration* } \\
\text { Type, duration and frequency of the } \\
\text { executing force* } \\
\text { Force transfer and gripping conditions } \\
\text { Hand-arm posture during manual work } \\
\text { processes } \\
\text { Body posture } \\
\text { Unfavourable working conditions } \\
\text { Work organisation/distribution of this type of } \\
\text { physical workload during the shift }\end{array}$ & $\begin{array}{l}\text { Assembly activities (eg, } \\
\text { installation of electrical } \\
\text { appliances), sorting, } \\
\text { cutting, cashiering, } \\
\text { manually controlling, } \\
\text { pipetting, microscopy, } \\
\text { joining, turning, cutting, } \\
\text { moving, wrapping }\end{array}$ \\
\hline
\end{tabular}

${ }^{*}$ Compared with the existing KIM, this key indicator is modified considerably in the revised version.

†Compared with the existing KIM, this key indicator is added in the revised version.

determination of face validity, reliability, convergent validity, criterion validity and further aspects of utility.

Setting of the study will be workplaces in voluntarily participating companies of different sizes and branches (including, eg, industry, handicraft, healthcare) in Germany.

\section{Characteristics of participants}

For the analysis of criterion validity, male and female employees, 19-65 years of age, at workplaces with different types and levels of physical workloads will be recruited, who have worked at the workplaces considered for at least 3 months and are proficient in the German language. For each type of physical workload (total of six types: LHC, PP, MHO, BF, ABP, BM) and for each of four exposure levels as rated by experts beforehand (low, slightly increased, substantially increased and high), approximately 40-50 employees will be recruited (assuming predominantly uniform exposures in each group). The aim is to cover all employees of the selected workplaces. Employees participate in the study voluntarily. The employer makes participation in the study possible for the employees within the working time. Only if more than 20 volunteers are engaged in the same workplace, the participants will be selected randomly. The study population can be calculated as follows: 6 types of physical workloads $\times 4$ exposure levels $\times 50$ subjects per type of physical workload and exposure level=1200 subjects. Assuming that, at each workplace, an average of 10 employees can be recruited, 120 workplaces need to be observed and documented. It is intended to analyse about five workplaces per type of physical workload and exposure level. Approximately 10 employees per workplace will be interviewed by ergonomists and interviewed and examined by physicians.

The data gathered during observation and documentation of the 120 workplaces will also be used for the determination of convergent validity, reliability and further aspects of utility. For the determination of inter-rater reliability, 12 users of the KIMs are needed to represent future users. Typical users of these kinds of assessment methods ideally are occupational health and safety stakeholders or industrial engineers in the companies. From these 12 users, six pairs will be formed (one pair per type of physical workload), each observing 20 workplaces. This will result in 120 double ratings. No specific skills will be required for this tests, but the users will get a standardised introduction in the methods. The 
Table 2 New KIMs (to be developed)

\begin{tabular}{|c|c|c|c|}
\hline Acronym & $\begin{array}{l}\text { Focus of this key indicator } \\
\text { method (KIM) }\end{array}$ & $\begin{array}{l}\text { Key indicators to be considered in this } \\
\text { KIM }\end{array}$ & Examples \\
\hline KIM-BF & $\begin{array}{l}\text { Whole-body forces with mostly } \\
\text { stationary force application. }\end{array}$ & $\begin{array}{l}\text { Daily duration } \\
\text { Type, duration and frequency of the } \\
\text { executing force } \\
\text { Symmetry of the application of force } \\
\text { Body posture } \\
\text { Unfavourable working conditions } \\
\text { Work organisation/distribution of this } \\
\text { type of physical workload during the shift }\end{array}$ & $\begin{array}{l}\text { Working with winches, work } \\
\text { with levers, working with } \\
\text { pneumatic hammers, working } \\
\text { with chainsaws }\end{array}$ \\
\hline KIM-ABP & $\begin{array}{l}\text { Awkward body postures } \\
\text { including any strenuous } \\
\text { postures, which are } \\
\text { predestinated by the work } \\
\text { process and are long lasting }\end{array}$ & $\begin{array}{l}\text { Duration and temporal distribution of } \\
\text { different trunk postures } \\
\text { Duration and temporal distribution of } \\
\text { sitting/walking/standing during the day } \\
\text { Duration and temporal distribution of } \\
\text { hands above shoulder and far from body } \\
\text { Duration and temporal distribution of } \\
\text { kneeling, squatting } \\
\text { Unfavourable working conditions }\end{array}$ & $\begin{array}{l}\text { Steel fixing (concrete), manual } \\
\text { welding, ceiling mounting, } \\
\text { work at the microscope, } \\
\text { working inside of tanks, } \\
\text { microsurgery }\end{array}$ \\
\hline KIM-BM & $\begin{array}{l}\text { Body movements to a place of } \\
\text { work or in a work area, which } \\
\text { will be assessed independently } \\
\text { of applying force }\end{array}$ & $\begin{array}{l}\text { Body movement and eventually carried } \\
\text { load } \\
\text { Location of the load centre } \\
\text { Body movement when driving with } \\
\text { transport device } \\
\text { Driveway conditions (if work task } \\
\text { includes driving) } \\
\text { Unfavourable working conditions } \\
\text { Work organisation/distribution of this } \\
\text { type of physical workload during the shift }\end{array}$ & $\begin{array}{l}\text { Climbing tower cranes, control } \\
\text { inspections in channels, } \\
\text { maintenance on furnaces }\end{array}$ \\
\hline
\end{tabular}

content of this introduction will be used later as framework for a guideline which will be disseminated with the method.

\section{Working hypotheses}

The working hypotheses ( $\mathrm{WH}$ ) include the examination of different quality criteria of the KIMs:

- WH 1: The KIMs are an adequate reflection of the construct to be measured (face validity).

- WH 2: At the completion of the KIMs, no relevant deviations occur between different users assessing the same workplaces (reliability).

- WH 3: Assessing workplaces using the KIMs and other screening methods measuring the same type of physical workload will result in no relevant differences (convergent validity).

- WH 4: It is assumed that employees at workplaces with high physical workloads show adverse health-related outcomes (eg, musculoskeletal symptoms) more frequently than non-exposed workers. It is assumed that high-risk scores derived in the assessment of workplaces with the KIMs are associated with a high prevalence of musculoskeletal symptoms and disorders (criterion validity or content validity regarding hypotheses testing).

The selection of the quality criteria described in the working hypotheses is derived from a systematic evaluation of observational methods assessing biomechanical exposures at work. ${ }^{9}$ For the analysis of the quality criteria, the recommendations of the COSMIN checklist (COnsensus-based Standards for the selection of health Measurement INstruments) will be taken into account. ${ }^{19}$ The reporting of the results of this observational study will also consider the recommendations of STROBE (Strengthening The Reporting of OBservational studies in Epidemiology). ${ }^{20}$

\section{Instruments and methods}

The instruments and methods for the assessment of exposures and outcomes (ie, questionnaire, medical diagnostic tool, assessment of working conditions) used in this survey have been used in a similar form in other studies by several authors. The authors of the present study used them for the assessment of musculoskeletal symptoms in 
office workers $^{21}$ and in a former validation study of the KIM-MHO. 2223

- Assessment of exposure

- Ergonomic work procedure analysis and assessment of technical procedures for the documentation of working conditions

Application of the KIMs:

- Application of the six KIMs based on the exposure assessment.

- Assessment of health outcomes:

- Standardised questionnaire for a survey among the employee.

- Medical diagnostic tool for the physical examination of the employees.

Ergonomic work procedure analysis for the assessment of exposures

The basis for the evaluation of the workplaces is an ergonomic work procedure analysis with detailed assessment of exposures during the shift. An a priori defined set of items of a complex workplace analysis was developed. Results are recorded in a large modular document for a detailed description of the work tasks and the workplace. A workplace typically consists of a number of different work tasks. Duration and frequency of all work tasks are documented in a way that the KIMs, as well as further screening methods chosen for the testing of convergent validity, can be completed. The ergonomic work procedure analysis covers in principle all relevant objective characteristics that result from the type of work and the working conditions. Individual characteristics during work execution, random disruption of the workflow or unusual conditions will not be considered. Principal components of the work procedure analysis are as follows:

1. Metadata of the workplace, such as name and type of activity, precise list of work tasks, professional qualification requirements, position of employees, complexity of the activity, number of employees at the workplace, gender and age distribution, shift system, typical working time and predetermination of the work task;

2. Number and type of work task and for every work task detailed information, for example, about temporal distribution of this work task during the shift, determination of type of work (eg, load handling, applying force, body posture, joint positions); and

3. Basic description of other relevant exposures, such as noise level, lighting, vibration and hazardous materials.

\section{Application of the KIMs}

The application and validation of the KIMs are the central goals of this research project and will be completed based on the ergonomic work procedure analysis. The KIMs contain an objective requirement and description of exposures and identify potential threats to physical overload. The KIMs include job characteristics and their interaction. The key indicators are classified in different scales. The scales correspond to conditions in practice and range from a minimum to maximum or optimum to poor. The classification of these scales indicates bottlenecks for each category and key indicator. By multiplying the scale value of the daily duration and frequency of activity with the sum of the other scale scores, a total value can be calculated. This calculated sum score can be allocated to an exposure level and one of four risk categories, an approach already used in existing KIMs. ${ }^{14}$ The four risk categories reflect the increase in the probability of physical overload and correspondingly the increase in frequency of adverse health effects related to the given physical workload from low (reference group) to high load situations (see above, section 'Previous development and validation of the KIMs').

An overview of the KIMs, including a brief description of the types of physical workloads, the key indicators considered and some examples of typical work tasks, is provided for the already existing KIMs in table 1 and for the KIMs under development in table 2. The revisions of the already existing KIMs include small changes (eg, wording) to harmonise the six KIMs and major changes, such as the modification of the time rating and the implementation of new aspects (eg, load handling conditions and location of the load during LHC).

Standardised questionnaire for the assessment of health outcomes The employees' questionnaire (conducted in interview) is divided into four parts:

1. Personal details including sociodemographic data (eg, age, gender, years on the job, leisure time activities), general information about current and former occupational activities (eg, type and amount of physical workload, time pressure, shift work, working posture);

2. Subjective assessments of the exposure in the workplace (questionnaire of the subjective estimation of exposures (FEBA) ${ }^{24}$ );

3. Other psychosocial aspects (eg, job satisfaction, social support, commitment; extract from the COpenhagen PSychOsocial Questionnaire ${ }^{25}$ 26); and

4. Subjective perceived exertion of physical workload (Borg RPE scale ${ }^{27}$ ).

Medical diagnostic tool for the assessment of health outcomes The documentation of the medical interviews is based on the standardised Nordic questionnaires for the analysis of musculoskeletal symptoms. ${ }^{28}{ }^{29}$ To substantiate the statements of the employees about the musculoskeletal symptoms in the interviews, a physical examination is performed after the interview. In order to derive specific tentative medical diagnoses, a list of standard diagnoses of musculoskeletal disorders is considered. The medical diagnostic tool used in the present study was derived from a SALTSA study ${ }^{30}$ and supplemented by a multistage diagnosis $^{31}$ and further examination techniques. ${ }^{32}$ The diagnostic tool consists of a documentation sheet and a reference sheet. The documentation sheet is divided 
into three parts. Part A is a general survey to document painful or symptomatic body regions. Part B deals with specific examination techniques to be carried out if pain or symptoms in specific regions were documented in part A. According to these results and with assistance of a reference sheet, tentative diagnoses can be assigned using a list of diagnoses in part $\mathrm{C}$.

These are:

Diseases of the upper extremities

- Cervical/cervicocephal syndrome

- Cervicobrachial syndrome

- Rotator cuff syndrome, adhesive capsulitis of shoulder

- Medial and lateral epicondylitis

- Flexor/extensor peritendinitis/tendosynovitis of forearm/wrist region

- Carpal tunnel syndrome

- Osteoarthritis of the joints of the distal upper extremities

Disorders of the lower back

- Low back pain/lumbago

- Lumbar facet syndrome-pseudo-radicular syndrome

- Lumbar radicular syndrome

Disease of the lower extremities

- Hip osteoarthritis

- Knee osteoarthritis (including chondromalacia patellae)

- Meniscus lesion

- Static insufficiency of foot

- Varicosis of the leg veins

Further relevant conditions not included in this list are also recorded.

\section{Data analysis plan}

Analysis of WH 1 (face validity)

Face validity was derived from preliminary work and a feasibility study, which was done in preparation prior to the main study. ${ }^{33}$ For the determination of face validity, no statistic procedures are used. As mentioned above, the six KIMs were developed based on our own experiences and research during the last decades, including an extensive search of peer-reviewed scientific articles and other grey literature concerned with methods for the assessment of working conditions associated with physical workloads. In 2015, the feasibility of the six KIMs was field tested at 114 workplaces in 40 different companies. At each workplace, the KIMs were completed and discussed with the respective occupational health and safety stakeholders in the companies and developed further iteratively. Overall, the KIM forms were completed 615 times during this process. According to these field tests, the results seemed to be plausible to the stakeholders involved, and all relevant aspects seemed to be implemented. ${ }^{33}$ The results of this feasibility study were integrated in modified drafts of the KIMs which are basis for the scientific validation described in the following research goals and chapters.
Analysis of WH 2 (reliability)

It will be analysed whether relevant deviations between different users assessing the same workplaces occur. The reliability will be determined by examining the independence of results assessed by different individuals (occupational health and safety stakeholders). Descriptive statistics (mean, median, variance and range) will be used to illustrate the distribution of different workplace assessments of the involved experts. Inter-rater reliability for multiple raters will be analysed using standard video sequences of typical workplaces for risk assessment and rating these videos by a group of selected experts under standardised conditions. ${ }^{34}$

\section{Analysis of WH 3 (convergent validity)}

It will be analysed whether relevant differences occur during assessment of workplaces with the KIMs and with other screening methods measuring the same type of physical workload. The descriptions of the 120 workplaces gathered in the cross-sectional study are the data basis for the determination of the convergent validity. During the selection of the workplaces to be included in the study, an equal distribution of the six types of physical workloads and the four exposure levels will be taken into account. It is assumed that an average of five work tasks can be analysed at any workplace. Thus, around 600 work task descriptions will be available, 100 descriptions per type of physical workload. Each KIM provides a score of 1 point to about 200 points (theoretically, point values $>1000$ are possible; however, these values are unlikely to appear under real conditions). If the respective comparison method also produces a score, correlation analyses will be performed. ${ }^{35}$ The correlation coefficient and the mean value will be taken into account. If the comparison method does not produce a score (eg, differs only dichotomously between 'green' and 'red'), Cohen's kappa ${ }^{36}$ is calculated using the exposure levels of the KIMs. For the six KIMs expressing six types of physical workloads, other existing methods were selected for comparison which meet as many of the criteria as possible below:

- description of quality criteria,

- large degree of dissemination,

- plausible and comprehensible model, and

- matching ability with the concept presented here.

At the time of the adoption of this study protocol, among others, the following methods are suggested for the examination of convergent validity: REBA, ${ }^{18}$ assessment technique for postural loading on the upper body, ${ }^{37}$ Assessment of Exposure to Occupational Repetitive Actions of the Upper Limbs, ${ }^{38}$ Threshold Limit Value for Mono-Tasks Handwork Hand Activity Level, ${ }^{39}$ Strain-Index, ${ }^{40}$ NIOSH Lifting Equation, ${ }^{17}$ Group-Evaluation-Tables, ${ }^{41}$ Garg-Procedure, ${ }^{42}$ procedure for the assessment of workloads ${ }^{43}$ and the former versions of the $\mathrm{KIMs},{ }^{11-13}$ as these fit more or less with one or more of the six types of physical workload (LHC, PP, MHO, BF, ABP 


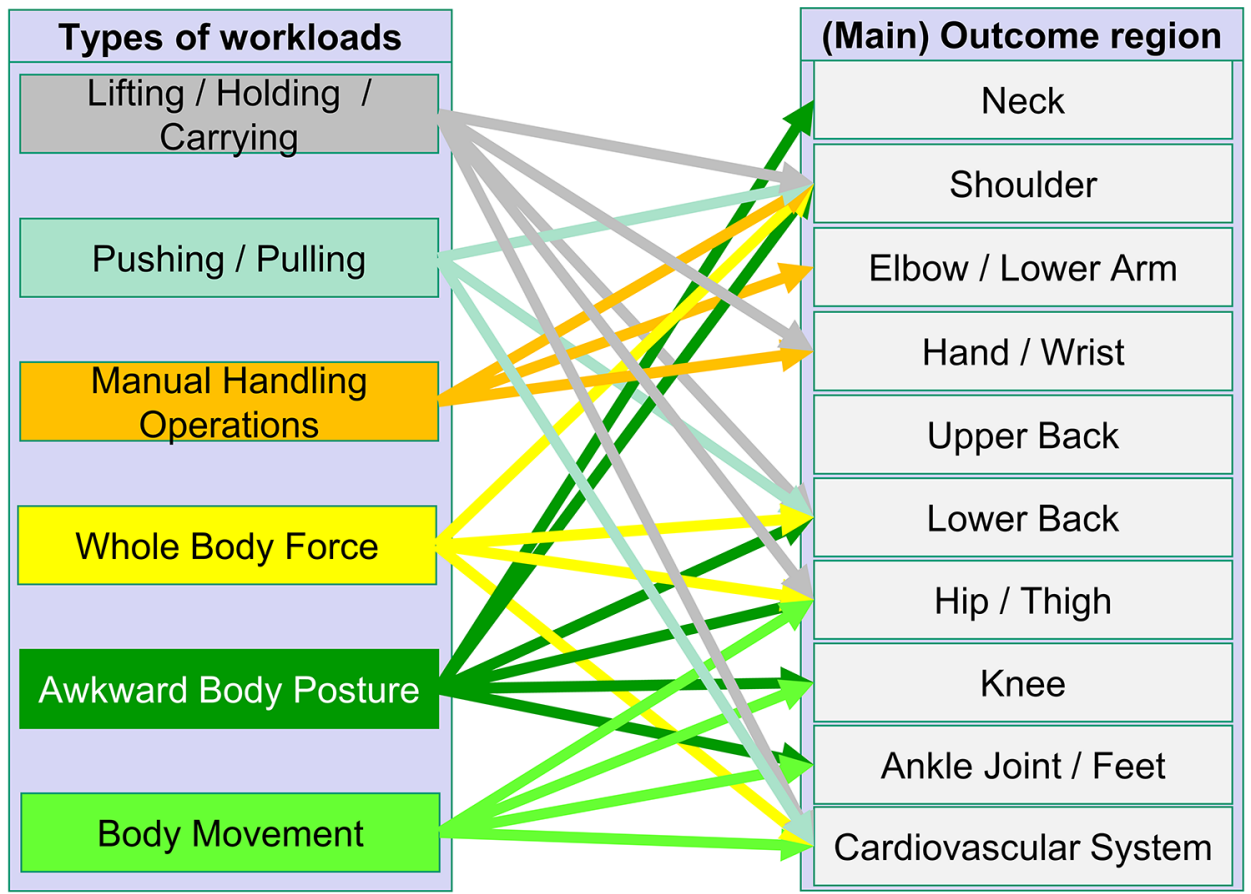

Figure 2 Types of physical workloads and relation to the main outcome regions. For each type of physical workload, one specific key indicator method is developed and validated.

or $\mathrm{BM}$ ) and therefore to one or more of the six newly developed and redesigned KIMs.

Analysis of WH 4 (criterion validity or content validity regarding hypotheses testing)

It will be analysed whether employees at workplaces with high physical workloads show adverse health-related outcomes (eg, musculoskeletal symptoms) more frequently than non-exposed workers considering relevant confounders such as age, gender, constitution or disposition. It is assumed that high scores derived in the assessment of workplaces with the KIMs are associated with a high frequency of musculoskeletal symptoms in exposed workers. Accordingly, low scores in the KIMs resulting at workplaces with low physical workloads are associated with a low frequency of musculoskeletal symptoms in workers. For each type of physical workload and each KIM, the (main) outcome region(s) considered vary. The approximate impact of physical workloads and outcomes is described schematically in figure 2.

Effect estimates for dichotomous outcomes (prevalence of symptoms) are prevalence ratios with $95 \%$ CIs per type of physical workload and exposure level, as determined by the KIMs. Effect estimates for continuous outcomes (eg, perceived exertion) are beta-estimators (increment) with $95 \%$ CIs per type of physical workload and exposure level, as determined by the KIMs. The lowest exposure level is regarded as the reference category (internal control group). The increments are estimated using linear regression models (IBM-SPSS-Statistics procedure Genlin) under consideration of confounders (at least: age, sex, body mass index (BMI) and body height). For each type of physical workload (each KIM), the following models are calculated:
- minimally adjusted models (age, gender),

- moderately adjusted models (age, sex, BMI, body height and other types of physical exposures), and

- maximally adjusted models (age, sex, BMI, body height, other types of physical workloads, other occupational exposures and other confounders, see table 3$)$.

Primarily, the moderately adjusted models will be interpreted. As far as possible, based on the regression models, post hoc assessments of prevalences of the outcomes for each type of physical workload will be conducted. Subjects are excluded from the analyses, if missing data in the different body regions occur. Sensitivity analyses are intended regarding regional distribution of the workplaces, company characteristics (size, branches and so on) and gender. For an overview of the outcomes, exposures, predictors and potential confounders, see table 3. The analysis of effect modifiers is not included in this study.

\section{Sample size calculation}

For power or sample size calculation, the EpiManager-Software $^{44}$ and $\mathrm{G}^{*}$ Power $^{45}$ were used.

\section{Power for determination of reliability}

For the determination of reliability (WH 2), 12 users of the KIMs are needed, in order to represent future potential users. From these 12 users, six pairs will be formed, each observing 20 workplaces. This will result in 120 double ratings. As statistical measures, correlation coefficients are calculated, and comparisons of mean values are carried out. The assessment of conformity is based on the following categories: values $\leq 0.3$ small; $>0.3$ to $<0.5$ low; 0.5 to $<0.7$ good; $\geq 0.7$ high correlation. 
Table 3 Description of outcomes, exposures, predictors and potential confounders

\begin{tabular}{|c|c|c|c|}
\hline Outcomes & Exposures & Predictors & Potential confounders \\
\hline $\begin{array}{l}\text { 1. Prevalence of } \\
\text { musculoskeletal symptoms } \\
\text { (7-day and 12-month } \\
\text { prevalence) in the following } \\
\text { body regions: } \\
\text { Neck } \\
\text { Shoulder } \\
\text { Elbow/lower arm } \\
\text { Hand/wrist } \\
\text { Upper back } \\
\text { Lower back } \\
\text { Hip/thigh } \\
\text { Knee } \\
\text { Ankle joint/feet } \\
\text { 2. Tentative medical } \\
\text { diagnoses } \\
3 \text {. Exposure related reaction } \\
\text { of the cardiovascular } \\
\text { system described by } \\
\text { perceived exertion (Borg } \\
\text { RPE scale) }\end{array}$ & $\begin{array}{l}\text { Six types of physical } \\
\text { workload: } \\
\text { Manual lifting, holding and } \\
\text { carrying of loads (LHC) } \\
\text { Manual pulling and } \\
\text { pushing of loads (PP) } \\
\text { Manual handling } \\
\text { operations (MHO) } \\
\text { Whole-body forces (BF) } \\
\text { Awkward body postures } \\
\text { (ABP) } \\
\text { Body movement (BM) }\end{array}$ & $\begin{array}{l}\text { Predictors are the exposure levels } \\
\text { of the KIMs: } \\
\text { Level } 1 \text { (reference category): } \\
\text { low exposure, physical } \\
\text { overload is unlikely to occur } \\
\text { Level 2: slightly increased } \\
\text { exposure, physical overload } \\
\text { possible for particular groups of } \\
\text { employees } \\
\text { Level 3: substantially increased } \\
\text { exposure, physical overload } \\
\text { possible } \\
\text { Level 4: high exposure, physical } \\
\text { overload is likely to occur }\end{array}$ & $\begin{array}{l}\text { Sex (split variable) } \\
\text { Age } \\
\text { Body mass index (BMI) } \\
\text { Body height } \\
\text { Bther types of physical } \\
\text { workload* } \\
\text { Other occupational } \\
\text { exposures (eg, noise, } \\
\text { vibrations) } \\
\text { Job satisfaction } \\
\text { Quantitative demands } \\
\text { Cognitive demands } \\
\text { Workplace insecurity } \\
\text { Influence at work } \\
\text { Social support } \\
\text { Social relations }\end{array}$ \\
\hline
\end{tabular}

*If for example, tested for the exposure LHC, the other exposures, which might occur during the shift (PP, MHO, BF, ABP and BM), are considered as confounders. For a rough overview, see figure 2.

In order to demonstrate a correlation (correlation coefficient, r) of 0.7 (alpha 0.05 and beta 0.8 ), about 15 double observations would be necessary. For a correlation of $0.8,10$ double observations would be necessary. The target of 20 double observations per type of physical workload should ensure an adequate study power.

Power for determination of convergent validity

For the determination of convergent validity (WH 3), workplaces will be assessed by scientists experienced in ergonomics using the KIMs and further screening methods assessing the same type of physical workload. A correlation coefficient between the KIM and an alternative screening method of $\mathrm{r}=0.5$ or higher is considered to be an adequate correlation. ${ }^{35}$ To show that two methods correlate at least with an $r$ of 0.5 or higher (H1: $r>0.5$ vs $\mathrm{H} 0: \mathrm{r}=0), 56$ sets of recorded data are required for each of the six KIMs. If only 30 sets of recorded data per process could be evaluated, it can be shown that the two methods correlate with an $\mathrm{r}$ of about 0.8 or higher ( $\mathrm{H} 1: \mathrm{r}>0.8$ vs $\mathrm{H} 0: \mathrm{r}=0$, alpha $<0.05$, beta 0.8 ). If the comparison method does not produce a score but only categories, Cohen's kappa ${ }^{36}$ is calculated. In this case, 100 datasets are needed to show statistically relevant correlations.

\section{Power for determination of criterion validity}

As described in $\mathrm{WH} \mathrm{4}$, it is assumed that employees at workplaces with high physical workloads show adverse health-related outcomes more frequently than non-exposed workers. The outcomes to be considered in this study are as follows (table 4):

Table 4 Expected outcomes according to exposure levels of the key indicator methods (KIMs)

\begin{tabular}{llll}
\hline $\begin{array}{l}\text { Exposure levels of } \\
\text { the KIMs }\end{array}$ & $\begin{array}{l}\text { 1. Prevalence of musculoskeletal } \\
\text { symptoms }\end{array}$ & $\begin{array}{l}\text { 2. Prevalence of tentative } \\
\text { diagnoses }\end{array}$ & $\begin{array}{l}\text { 3. Perceived exertion } \\
\text { (Borg RPE scale) }\end{array}$ \\
\hline Low & Reference group & Reference group & Very light \\
Slightly increased & 7-day prevalence increased & $\begin{array}{l}\text { 12-month prevalence hardly } \\
\text { increased }\end{array}$ & Light
\end{tabular}

Acceptance level

\begin{tabular}{llll}
$\begin{array}{l}\text { Substantially } \\
\text { increased }\end{array}$ & $\begin{array}{l}\text { 7-day prevalence significantly increased } \\
\text { (at least double) }\end{array}$ & $\begin{array}{l}\text { Acceptance level } \\
\text { increased }\end{array}$ & \multicolumn{1}{c}{$\begin{array}{c}\text { Tolerance level } \\
\text { High }\end{array}$} \\
\hline
\end{tabular}


1. Prevalence of musculoskeletal symptoms (7 days and 12 months) in nine body regions (figure 2),

2. Prevalence of tentative diagnoses, and

3. Perceived exertion (Borg RPE scale). ${ }^{27}$

Power for the outcome 'prevalence of musculoskeletal symptoms' The minimum size of study population (at least 40-50 subjects per exposure level, targeted in 'characteristics of the participants in the study') is based on the power calculation. The 7-day prevalence of MSDs among males and females without physical workloads (office workers) was assessed in preliminary studies. ${ }^{21}$ The 7-day prevalence of MSDs for women was between $30 \%$ (cervical spine) and 5\% (hip, ankles) and for men between 20\% (cervical spine) and $5 \%$ (ankles) or 2\% (hip). The 12-month prevalence of MSDs in men and women without physical workloads was significantly higher, from $50 \%$ to $65 \%$ (cervical spine) to $10 \%$ (hip, ankle). Assuming an alpha error of $5 \%$ and a beta error of $80 \%$, in a group size of 40 persons exposed and 40 persons not exposed, and assuming a prevalence of $5 \%$ in the reference group, a prevalence ratio of 6.5 is significantly increased. If the prevalence of MSDs in the reference group is $20 \%$, prevalence differences are detectable by a factor of 2.5. Prevalence differences of this amount between non-exposed (exposure level: low) and highly exposed employees (exposure level: high) were observed in the preliminary study mentioned above. It is therefore expected that variations in prevalence of factors of at least 2-6 will be detectable, when comparing the two highest exposure categories by KIM with the lowest exposure level (reference group).

\section{Power for the outcome 'prevalence of tentative diagnoses'}

Due to the expected relatively low incidence of diagnoses in the working population, no statistically significant increase in the prevalence of tentative diagnoses is expected. However, an increasing trend with increasing physical workloads from exposure level 'low' to exposure level 'high' is expected.

\section{Power for the outcome 'perceived exertion (Borg RPE scale)'}

The highest limitations in power calculation according to criterion variability result from dichotomous variables as described in the section above (power for the outcome 'prevalence of musculoskeletal symptoms'). Therefore, the power of the study according to continuous variables (such as perceived exertion) is high due to the fact that 1200 subjects will be included in this study. Considering the large number of subjects, small differences of continuous variables between risk category groups are detectable.

\section{Quality control and assurance}

The use of standardised and-if available and appropriate-already validated and/or evaluated screening methods as comparison or reference methods ensures high quality of work. All questionnaires will be completed during a face-to-face interview. The work-related physical examination will be performed by trained external physicians. A standardised procedure for physical examination is guaranteed by the specific standardised training of the physicians. Remembering earlier symptoms in a retrospective period could involve a recall bias. In order to minimise the bias and to get a more detailed overview, we ask for the past 7-day prevalence and the 12-month prevalence of symptoms. In addition, a physical examination is carried out. The observation of these three outcomes together might reduce the recall bias. According to the selection criteria, only workers are included who are actually working at the workplaces. Workers with sickness absence cannot be considered in the recruitment. This could imply a healthy worker effect. The total number of workers at a workplace is requested of the companies and the number of sick leave days in the last 12 months is enquired of the volunteers. The information is considered in subanalyses to get an impression of the extent of this issue.

\section{What this study adds}

In this study, new KIMs for practical risk assessment of physical workloads are developed, and these new KIMs, as well as the already existing KIMs, will be validated. The KIMs are a modular tool kit of practical screening methods for assessing the risk factors associated with work-related musculoskeletal disorders. In addition, the study will increase the knowledge concerning the correlation between specific MSDs and characteristics of physical workloads. With this knowledge, a better classification of occupational hazards with regard to MSDs will be available in future. This may lead to more specific prevention strategies.

\section{ETHICS AND DISSEMINATION}

\section{Ethics approval and consent to participate}

The study was planned and conducted in accordance with the German Medical Professional Code and the Declaration of Helsinki of $2013,{ }^{46}$ as well as the German Federal Data Protection Act. ${ }^{47}$

The design of the study was examined by the ethics committee of the Technical University Darmstadt. The protocol achieved a positive vote (approval no. EK15/2015 2015-09-22 as supplement to EK2/2013 201307-04) and the ethics committee of the Medical Faculty of the University of Tübingen (004/2016BO2). The study was started after the ethics committees gave their written and unrestricted approval.

Employees participate in the study voluntarily. They can end their participation at any time without reason and without negative consequences, for example, for their job. Written informed consent for participation is obtained before the survey. Employees receive written and verbal information about the main features of the study as well as about potential benefits for their health and their contribution to the common public welfare. If they accept the conditions of the study and their participation, 
they document their consent with their signature. A copy of this statement is intended to be kept by the employee for later reference or cancellation of participation. All original documents are treated according to the German Federal Data Protection Act. A comprehensive data protection concept was approved by the data protection officer of the BAuA.

\section{Timeframe of the study and dissemination of results}

The study team started the planning of this project in 2012. The data collection for the cross-sectional study then started in spring of 2016 and will end in summer 2017. Description and analysis of the data will be done in 2017. It is intended to present the approved or revised KIMs to the public in 2018. Results will be published in peer-reviewed journals, presented at international meetings and disseminated to actual users for practical application. Potential users include occupational safety and health stakeholders in companies, industrial engineers, ergonomists, occupational health physicians, employers and employees associations, and insurance companies or research facilities.

\section{Author affiliations}

${ }^{1}$ Institute of Occupational Health, Safety and Ergonomics (ASER), Wuppertal, Germany

${ }^{2}$ University of Wuppertal, School of Mechanical Engineering and Safety Engineering, Chair of Human Engineering, Wuppertal, Germany

${ }^{3}$ Federal Institute for Occupational Safety and Health (BAuA), Berlin, Germany ${ }^{4}$ ArbMedErgo Consultant, Hamburg, Germany

Acknowledgements The definitions of six types of physical workloads as well as the underlying theoretical concept of risk assessment were developed within a consensual process involving all MEGAPHYS partners. All authors of this manuscript are MEGAPHYS partners of BAuA. Further MEGAPHYS partners are the Institute for Occupational Safety and Health of the German Social Accident Insurance (IFA), the Institute of Ergonomics at the Darmstadt University of Technology (IAD) and the Leibniz Research Centre for Working Environment and Human Factors. BAuA and IFA are responsible for the recruitment of $50 \%$ of the workplaces each. IFA contributes to the documentation of all 120 workplaces. Institute of Occupational Health, Safety and Ergonomics, with BAuA, and IAD are each responsible for the documentation of $50 \%$ of the workplaces and the execution of $50 \%$ of the described interviews. The physical examinations of the employees are performed by trained physicians of the Kern Medical Engineering, Frankfurt, in cooperation with Professor Rieger, head of the Institute of Occupational and Social Medicine and Health Services Research, University Hospital of Tuebingen. The authors thank Dr Paul Kahle for the English language check.

Contributors All authors were involved in the conception and design of the study and the preparation of this manuscript. US developed the first drafts of the key indicator methods (KIMs) and initiated this study. AK and FL concretised the salient content points of this protocol, such as selection of validation criteria and power calculation. AK had the lead management in preparation of the study protocol. US, AK, PS, HG, AS, BH, MS and FB form the development team of the new KIMs. all Authors were closely involved in the planning and development of the study design and preparing the study protocol. All authors read and approved the final manuscript.

\section{Competing interests None declared.}

Patient consent Focus of our study is on employees, not patients. Employees participate in the study voluntarily. They can end their participation at any time without reason and without negative consequences, for example, for their job. Written informed consent for participation is obtained before the survey. Employees receive written and verbal information about the main features of the study as well as potential benefits for their health and their contribution to the common public welfare. If they accept the conditions of the study and their participation, they document their consent with their signature. A copy of this statement is intended to be kept by the employee for later reference or cancellation of participation. All original documents are treated according to German Federal Data Protection Act. A comprehensive data protection concept was approved by the data protection officer of the Federal Institute for Occupational Safety and Health.

Ethics approval Ethics Committee of the Technical University Darmstadt (approval no. EK15/2015 2015-09-22 as supplement to EK2/2013 2013-07-04) and Ethics Committee of the Medical Faculty of the University of Tübingen (004/2016B02)

Provenance and peer review Not commissioned; externally peer reviewed.

Data sharing statement Data could not be shared as consent for this was not included in the informed consent process and not included in the ethics approval.

Open Access This is an Open Access article distributed in accordance with the Creative Commons Attribution Non Commercial (CC BY-NC 4.0) license, which permits others to distribute, remix, adapt, build upon this work non-commercially, and license their derivative works on different terms, provided the original work is properly cited and the use is non-commercial. See: http://creativecommons.org/ licenses/by-nc/4.0/

(C) Article author(s) (or their employer(s) unless otherwise stated in the text of the article) 2017. All rights reserved. No commercial use is permitted unless otherwise expressly granted.

\section{REFERENCES}

1. Bernard BP; U.S Department of Health and Human Services. Musculoskeletal disorders and Workplace factors. Public Health Services. Centers for Disease Control and Prevention. Cincinnati: National Institute for Occupational Safety and Health, 1997.

2. da Costa BR, Vieira ER. Risk factors for work-related musculoskeletal disorders: a systematic review of recent longitudinal studies. Am J Ind Med 2010;53:285-323.

3. Petit $A$, Roquelaure $Y$. Low back pain, intervertebral disc and occupational diseases. Int J Occup Saf Ergon 2015;21:15-19.

4. Descatha A, Albo F, Leclerc A, et al. Lateral epicondylitis and physical exposure at work? A review of prospective studies and meta-analysis. Arthritis Care Res 2016;68:1681-7.

5. Newington L, Harris EC, Walker-Bone K. Carpal tunnel syndrome and work. Best Pract Res Clin Rheumatol 2015;29:440-53.

6. Holtermann A, Mortensen OS, Burr H, et al. Physical demands at work, physical fitness, and 30-year ischaemic heart disease and all-cause mortality in the Copenhagen Male Study. Scand J Work Environ Health 2010;36:357-65.

7. European Council (EC). Council Directive 89/391/EEC OSH "Framework Directive" of 12 June 1989 on the introduction of measures to encourage improvements in the safety and health of workers at work. 1989. https://osha.europa.eu/en/legislation/ directives/the-osh-framework-directive/1 (accessed 30 Nov 2016).

8. European Council (EC). Council Directive 90/269/EEC "Manual handling of loads" of 29 May 1990 on the minimum health and safety requirements for the manual handling of loads where there is a risk particularly of back injury to workers. https://osha.europa.eu/en/ legislation/directives/6 (accessed 30 Nov 2016).

9. Takala EP, Pehkonen I, Forsman M, et al. Systematic evaluation of observational methods assessing biomechanical exposures at work. Scand J Work Environ Health 2010;36:3-24.

10. Tompa E, Dolinschi R, de Oliveira $C$, et al. A systematic review of workplace ergonomic interventions with economic analyses. J Occup Rehabil 2010;20:220-34.

11. LASI. Länderausschuss für Arbeitsschutz und Sicherheitstechnik). Handlungsanleitung zur Beurteilung der Arbeitsbedingungen beim Heben und Tragen von Lasten. LASI-Veröffentlichung LV 9. 2001. http://lasi-info.com/uploads/media/lv9.pdf (accessed 30 Nov 2016).

12. LASI. Länderausschuss für Arbeitsschutz und Sicherheitstechnik). Handlungsanleitung zur Beurteilung der Arbeitsbedingungen beim Ziehen und Schieben von Lasten. LASI-Veröffentlichung LV 29. 2002. http://lasi-info.com/uploads/media/lv29_01.pdf (accessed 30 Nov 2016).

13. LASI. Länderausschuss für Arbeitsschutz und Sicherheitstechnik). Handlungsanleitung zur Beurteilung der Arbeitsbedingungen bei manuellen Arbeitsprozessen. LASI Veröffentlichung LV 57. 2013. http://lasi-info.com/uploads/media/lv57_02.pdf (accessed 30 Nov 2016).

14. Steinberg U, Caffier U, Liebers F. Assessment of Manual Material Handling Based on Key Indicators: German Guidelines. Karwowski W, ed. Handbook of Standards and guidelines in ergonomics and human factors. London: lawrence Erlbaum Associates, 2005:317-35. 
15. BAuA (Federal Institute of Occupational Safety and Health). Gefährdungsbeurteilung mithilfe der Leitmerkmalmethode [Risk Assessment based on Key Indicator Methods]. 2016. http://www. baua.de/leitmerkmalmethoden (accessed 15 Sep 2016).

16. Ditchen D, Brandstaedt F. MEGAPHYS - Entwicklung eines Methodenpakets zur Gefährdungsbeurteilung physischer Belastungen am Arbeitsplatz [Development of methods for risk assessment of physical workload in the workplace]. Technische Sicherheit 2015;5:17-23.

17. Waters TR, Putz-Anderson V, Garg A, et al. Revised NIOSH equation for the design and evaluation of manual lifting tasks. Ergonomics 1993;36:749-76.

18. Hignett S, McAtamney L. Rapid entire body assessment (REBA). Appl Ergon 2000;31:201-5.

19. Mokkink LB, Terwee CB, Patrick DL, et al. The COSMIN checklist for assessing the methodological quality of studies on measurement properties of health status measurement instruments: an international Delphi study. Qual Life Res 2010;19:539-49.

20. von Elm E, Altman DG, Egger M, et al. The Strengthening the Reporting of Observational Studies in Epidemiology (STROBE) statement: guidelines for reporting observational studies. Bull World Health Organ 2007;85:867-72.

21. Klussmann A, Gebhardt H, Liebers F, et al. Musculoskeletal symptoms of the upper extremities and the neck: a cross-sectional study on prevalence and symptom-predicting factors at visual display terminal (VDT) workstations. BMC Musculoskelet Disord 2008;9:96.

22. Klussmann A, Steinberg U, Liebers F, et al. The Key Indicator Method for Manual Handling Operations (KIM-MHO) - evaluation of a new method for the assessment of working conditions within a crosssectional study. BMC Musculoskelet Disord 2010;11:272.

23. Steinberg U, Liebers F, Klußmann A, et al. Bericht über die Erprobung, Validierung und Revision: Leitmerkmalmethode Manuelle Arbeitsprozesse. Bundesanstalt für Arbeitsschutz und Arbeitsmedizin: Dortmund , 2012.

24. Slesina W. Arbeitsbedingte Erkrankungen und arbeitsanalyse Arbeitsanalyse unter dem Gesichtspunkt der Gesundheitsvorsorge. Stuttgart: Enke, 1987.

25. Kristensen TS. A new tool for assessing psychosocial factors at work: the Copenhagen Psychosocial Questionnaire. TUTB Newsletter 2002;19-20:45-7.

26. Nuebling M, Stoessel U, Hasselhorn HM, et al. Methoden zur Erfassung psychischer Belastungen - Erprobung eines Messinstrumentes (COPSOQ). Schriftenreihe der Bundesanstalt für Arbeitsschutz und Arbeitsmedizin. Forschungsbericht Fb. 1058. Bremerhaven: NW-Verlag, 2005.

27. Borg G. Borg's Perceived exertion and pain scales. United States of America: Human Kinetics, 1998

28. Kuorinka I, Jonsson B, Kilbom A, et al. Standardised Nordic questionnaires for the analysis of musculoskeletal symptoms. Appl Ergon 1987;18:233-7.

29. Caffier G, Steinberg U, Liebers F. Praxisorientiertes Methodeninventar zur Belastungsbeurteilung im Zusammenhang mit arbeitsbedingten Muskel-Skelett-Erkrankungen. Schriftenreihe der Bundesanstalt für Arbeitsschutz und Arbeitsmedizin, Forschungsbericht Fb. 850. Bremerhaven: NW-Verlag, 1999.
30. Sluiter JK, Rest KM, Frings-Dresen MH. Criteria document for evaluating the work-relatedness of upper-extremity musculoskeletal disorders. Scand J Work Environ Health 2001;27 Suppl 1:1-102.

31. Grifka J, Peters T, Bär FF. Mehrstufendiagnostik Von Muskel-SkelettErkrankungen in der arbeitsmedizinischen Praxis. Bundesanstalt für Arbeitsschutz und Arbeitsmedizin (Hrsg.), Sonderschrift S 62. Bremerhaven: NW-Verlag, 2001.

32. Spallek M, Kuhn W. Funktionsorientierte körperliche Untersuchungssystematik: die fokus-Methode zur Beurteilung des Bewegungsapparates in der Arbeits- und Allgemeinmedizin. Heidelberg: Ecomed, 2009.

33. Brandstaedt F, Klussmann A, Schaefer A, et al. Pretesting of new key indicator methods in Germany using techniques of qualitative research. Ninth International Scientific Conference on the Prevention of Work-Related musculoskeletal disorders. PREMUS 2016. book of abstracts. Toronto: Institute for Work \& Health, 2016:140.

34. Bortz J, Lienert GA. Kurzgefasste Statistik für die klinische Forschung. Berlin: Springer, 2003.

35. Cohen J. Statistical power analysis for the behavioral sciences. Hillsdale, NJ: Lawrence Erlbaum Associates, 1988.

36. Cohen J. A coefficient of agreement for nominal scales. Educ Psychol Meas 1960;20:37-46.

37. Kee D, Karwowski W. LUBA: an assessment technique for postural loading on the upper body based on joint motion discomfort and maximum holding time. Appl Ergon 2001;32:357-66.

38. Occhipinti E. OCRA: a concise index for the assessment of exposure to repetitive movements of the upper limbs. Ergonomics 1998;41:1290-311.

39. Armstrong T. The ACGIH TLV for hand activity level. In: Marras WS, Karwowski W, Fundamentals and assessment tools for occupational ergonomics. Boca Raton, Florida: CRC Press, 2006:1-14.

40. Moore JS, Garg A. The Strain Index: a proposed method to analyze jobs for risk of distal upper extremity disorders. Am Ind Hyg Assoc $J$ 1995:56:443-58.

41. Spitzer $\mathrm{H}$, Hettinger T, Kaminsky G. Tafeln für den Energieumsatz bei körperlicher Arbeit. 6. Auflage. Berlin: Beuth, 1982.

42. Garg A, Chaffin DB, Herrin GD. Prediction of metabolic rates for manual materials handling jobs. Am Ind Hyg Assoc $J$ 1978;39:661-74.

43. Gebhardt $\mathrm{H}$, Müller $\mathrm{BH}$, Peters $\mathrm{H}$. Instrumente des Arbeits- und Gesundheitsschutzes: das Belastungs-Dokumentations-System (BDS) und die Beurteilung arbeitsbedingter Belastungen (BAB). REFA-Nachrichten 2003;56:8-18. ISSN 0033-6874.

44. EpiManager Software. www.baua.de/de/Informationen-fuer-diePraxis/Handlungshilfen-und-Praxisbeispiele/EpiManager.html (accessed 15 Sep 2016).

45. Faul F, Erdfelder E, Buchner A, et al. Statistical power analyses using $G^{*}$ Power 3.1: tests for correlation and regression analyses. Behav Res Methods 2009;41:1149-60.

46. World Medical Association (WMA). Declaration of Helsinki - Ethical Principles for Medical Research Involving Human Subjects. 2013 https://www.wma.net/policies-post/wma-declaration-of-helsinkiethical-principles-for-medical-research-involving-human-subjects (accessed 15 Nov 2016)

47. Federal Ministry of Justice and Consumer Protection: Federal Data Protection Act. https://www.gesetze-im-internet.de/englisch_bdsg (accessed 15 Nov 2016). 